\title{
AN OXLEY-BASED FORCE MODEL FOR MILLING OF HARDENED STEEL USING INDEXABLE MILLING TOOLS
}

\author{
C. Hopkins ${ }^{1}$, A. Hosseini*1 \\ ${ }^{1}$ Department of Automotive, Mechanical, and Manufacturing Engineering, Faculty of Engineering and Applied Science, \\ Ontario Tech University, Oshawa, Canada \\ *sayyedali.hosseini@uoit.ca
}

\begin{abstract}
The present paper describes a force model based on the Oxley's extended machining theory to predict cutting forces during milling of hardened steels. In this paper, an indexable milling tool with both roughing and finishing edge is analyzed. The accuracy of the cutting force model is verified by a series of face-milling experiments on hardened steel AISI 4340.
\end{abstract}

Keywords; face milling, Oxley model, force prediction, cutting forces, hardened steel

\section{INTRODUCTION}

The ability to predict the cutting forces generated during machining operations is valuable to further the understanding of these processes. By their nature, machining operations are nonlinear and complex processes to model and simulate. Among commonly used approaches to analyze milling processes, many methods rely on several experiments to determine empirical constants that are unique to that combination of work material and cutting tool. Therefore, these methods are normally timeconsuming to utilize because cutting constants for each combination of tool and workpiece material must be determined exclusively through experimentations. Oxley's extended machining theory does not require these empirical constants, making it more versatile. Oxley's model is compatible with the Johnson-Cook constitutive equation, which allows the cutting force model to use material properties to determine the cutting forces. This is extremely beneficial because only the JohnsonCook parameters for a certain material are needed in order to predict the cutting forces during the machining of that material. Implementing such a method saves computational and financial resources compared to time-consuming experiments to determine specific empirical constants for each tool-workpiece combination. In addition to the cutting parameters such as cutting speed and feed rate (or alternatively feed/tooth), the material properties of the workpiece being machined must also be known. Since Oxley's extended machining theory utilizes a material's Johnson-Cook parameters, those values must also be found. The Johnson-Cook parameters for hardened steel AISI 4340 are available in the literature [1].

Oxley's predictive machining theory was first described as a method of predicting cutting forces and temperatures by considering the high strain-rate nature of machining processes
[2]. This theory was originally developed considering an orthogonal cutting process. Many factors regarding an orthogonal cutting model can be carried over from the Merchant cutting model [3]. Other developments have been made to alter this model to apply to oblique cutting operations as well, such as the work done by $\mathrm{Hu}$ et al. [4], however this paper will focus on the application of the orthogonal model. Other works have been published modifying Oxley's machining theory to consider other geometrical parameters of the tool. One such work is the consideration of the effect of a tool's nose radius on the chip flow direction, done by Arsecularatne et al. [5].

Hastings et al. [6] verified the validity of the orthogonal cutting model through a series of turning experiments under different rake angles and cutting speeds. Regarding the application of this model to the milling process, the work done by Young et al. [7] further transformed the model to consider a single-tooth cutter. This work divided the chip and cutting zone into a series of radial elements, allowing for a greater fidelity in the investigation of stress distributions. The extension of Oxley's model to accept Johnson-Cook material properties allowed the model to be applied to any material for which these parameters are known [8]. Prior to this, the machining theory would be used backwards to determine material properties from cutting data gathered from experiments. An example of this can be seen from Bao and Stevenson [9]. This paper will consider the orthogonal model presented in Oxley's machining theory, and apply it to a cutter with two different cutting edges. One edge is used for rough cuts, while the other is used for finishing cuts.

\section{MATHEMATICAL MODEL}

Oxley's extended machining theory is based on a parallel shear zone model for machining $[8,10]$. The chip formation model proposed by Oxley is shown in Fig. 1. In the present paper, this model is applied repeatedly for every increment of the tool rotation to describe parameters like the tool geometry effects, uncut chip thickness, and shear zone location for that particular position.

TABLE I. VARIABLE RANGE

\begin{tabular}{|l|l|}
\hline Variable & Range \\
\hline$\phi$ & $10^{\circ}-45^{\circ}$ \\
\hline$C_{0}$ & $2-8$ \\
\hline$\zeta$ & $0.01-0.4$ \\
\hline
\end{tabular}




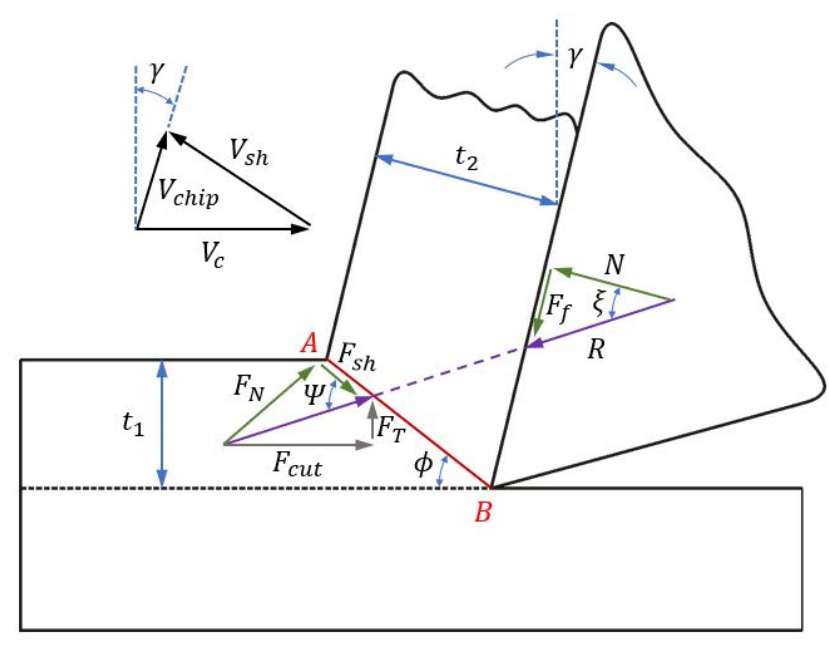

Figure 1. Chip formation model

Three parameters that cannot be exactly calculated for this model are the shear plane angle $\phi$, the ratio of shear plane length $A B$ to primary shear zone thickness $C_{0}$, and the ratio of tool-chip interface plastic zone thickness to chip thickness $\zeta$. Oxley's model states that these values will change so that the cutting force during the operation is minimized. Therefore, a range of possible values for each of these variables is defined. Each range is set such that all solutions still result in proper cutting of the material. The model is run in several loops, until the values for all three variables are determined. The ranges for each of these variables are displayed in Table 1 . At the beginning of the analysis, all variables are set to their minimum value.

In all milling processes, the uncut or undeformed chip thickness $t_{1}$ changes as the milling tool rotates. Thus, $t_{1}$ is equal to the instantaneous chip thickness at a certain tool position. In milling operations, this chip load can be calculated using (1).

$$
t_{1}=c \sin \theta
$$

For the Sandvik Coromant milling tools R390-020A20-11L that are utilized for experiments in this paper, the finishing edge experiences a smaller chip load than the roughing edge. This is due to the roughing edge being located slightly farther from the axis of rotation. This difference was measured as 50 microns. In the case of the finishing edge, the uncut chip thickness is calculated using (2).

$$
t_{1}=(c-0.05) \sin \theta
$$

The link between the Johnson-Cook constitutive equation and Oxley's extended machining model is a modified strain hardening exponent $n_{e q}$, which can be calculated using the known Johnson-Cook parameters, shown in (3) [8].

$$
n_{e q}=\frac{n B \varepsilon_{A B}^{n}}{A+B \varepsilon_{A B}^{n}}
$$

Where $A$ is the yield stress of the material, $B$ is the hardening stress, and $n$ is the strain-rate hardening exponent. With the inputs completely defined, the length of the shear plane $l$ and shear velocity $V_{s h}$ can be calculated using (4) and (5).

$$
\begin{gathered}
l=\frac{t_{1}}{\sin \phi} \\
V_{s h}=\frac{V_{c} \cos \gamma}{\cos (\phi-\gamma)}
\end{gathered}
$$

Using von Mises criteria, the equivalent plane strain and strain rate are found by (6) and (7) [10].

$$
\begin{gathered}
\varepsilon_{A B}=\frac{\eta_{A B}}{\sqrt{3}}=\frac{1}{2 \sqrt{3}} \frac{\cos \gamma}{\sin \phi \cos (\phi-\gamma)} \\
\dot{\varepsilon}_{A B}=\frac{\dot{\eta}_{A B}}{\sqrt{3}}=\frac{1}{\sqrt{3}} \frac{C_{0} V_{s h}}{l}
\end{gathered}
$$

As previously stated, Oxley's machining theory accounting for changes in temperature during the operation. First, a non-dimensional thermal number $E_{T}$ is determined using (8) [10].

$$
E_{T}=\frac{\rho C_{p} V_{c} t_{1}}{K}
$$

Where $\rho$ is the workpiece density $(\mathrm{kg} / \mathrm{m} 3), C_{p}$ is the specific heat of the workpiece $(\mathrm{J} / \mathrm{kgK})$, and $K$ is the thermal conductivity of the workpiece (W/mK). With $E_{T}$ known, the heat partition coefficient $\xi$ can be calculated using either (9) or (10) [10].

if $0.04 \leq E_{T} \tan \phi \leq 10 \rightarrow \xi=0.5-0.35 \log \left(E_{T} \tan \phi\right)$

$$
\text { if } E_{T} \tan \phi \geq 10 \rightarrow \xi=0.3-0.15 \log \left(E_{T} \tan \phi\right)
$$

Considering the plastic work being done in the primary shear zone, the average temperature $T_{A B}$ can be found using (11) [10]. In this paper, it is assumed that the value of the sensible heat coefficient $\lambda$ is 0.9 [10]. This value is chosen to follow the assumption that that sensible heat to latent heat ratio is $90 \%$ in favour of sensible heat.

$$
T_{A B}=T_{w}+\lambda \frac{(1-\xi) F_{s h} V_{s h}}{m_{\text {chip }} C_{p}}
$$

Where, $m_{\text {chip }}$ is the mass of the chip being removed. Using the average temperature at the primary shear zone, the average flow stress in the primary shear zone $\sigma_{A B}$ can found using the Johnson-Cook constitutive equation (12).

$$
\sigma_{A B}=\left(A+B \varepsilon_{A B}^{n}\right)\left(1+C \ln \left(\frac{\varepsilon_{\dot{A}}}{\dot{\varepsilon}_{0}}\right)\right)\left(1-\left(\frac{T_{A B}-T_{w}}{T_{M}-T_{w}}\right)^{m}\right)
$$

Where $m$ is the thermal softening coefficient, and $\dot{\varepsilon}_{0}$ is the reference strain rate. With the average flow stress now known, the angle between the shear plane and the resultant force $(\psi)$ can be determined using (13) [10].

$$
\tan \psi=1+2\left(\frac{\pi}{4}-\phi\right)-C_{0} n_{e q}
$$


The average friction angle between the tool and the chip being removed $\beta$ can be calculated using (14)

$$
\beta=\psi-\phi+\gamma
$$

Using these angles, the various force components can be calculated at any instance of the cut using (15)-(19) [10].

$$
\begin{gathered}
R=\frac{F_{s h}}{\cos \psi} \\
F_{f}=R \sin \beta \\
N=R \cos \beta \\
F_{c u t}=R \cos (\beta-\gamma) \\
F_{t}=R \sin (\beta-\gamma)
\end{gathered}
$$

At this point, the value of the cutting force $F_{c u t}$ must be stored for later analysis. All of the possible values for $F_{c u t}$ are compared to determine the final value of $\zeta$. Meanwhile, the deformed chip thickness can be found using (20).

$$
t_{2}=\frac{t_{1} \sin \psi}{\cos (\phi-\gamma)}
$$

In order to determine if these force values are accepted for the given inputs, various stresses must be calculated. To begin this section, the length of the contact area between the tool and the chip $L_{\text {int }}$ can be calculated using (21) [10].

$$
L_{\text {int }}=\frac{t_{1} \sin \psi}{\cos \beta \sin \psi}\left(1+\left(\frac{C_{0} n_{e q}}{3\left(1+2\left(\frac{\pi}{4}-\phi\right)-C_{0} n_{e q}\right)}\right)\right)
$$

The shear stress along the tool-chip interface $\left(\tau_{\text {int }}\right)$ is calculated using (22).

$$
\tau_{\text {int }}=\frac{F_{f}}{L_{\text {int }} W}
$$

Next, the maximum shear strain and the shear strain rate at this interface must be determined using (23) and (24) [10].

$$
\begin{gathered}
\varepsilon_{i n t}=\frac{\eta_{i n t}}{\sqrt{3}}=\frac{1}{\sqrt{3}}\left(2 \eta_{A B}+\frac{0.5 L_{i n t}}{\zeta t_{2}}\right) \\
\dot{\varepsilon}_{i n t}=\frac{\dot{\eta}_{i n t}}{\sqrt{3}}=\frac{1}{\sqrt{3}}\left(\frac{V_{\text {chip }}}{\zeta t_{2}}\right)
\end{gathered}
$$

Where $\eta_{A B}$ can be calculated by rearranging (6).

The maximum temperature change in the chip during cutting $\Delta T_{m}$ can be calculated using (25) and (26) [10].

$$
\begin{gathered}
\log \left(\frac{\Delta T_{m}}{\Delta T_{c}}\right)=0.06-0.195 \xi \sqrt{\frac{E_{t} t_{2}}{t_{1}}}+0.5 \log \left(\frac{E_{T} t_{2}}{L_{\text {int }}}\right) \\
\Delta T_{c}=\frac{F_{f} V_{\text {chip }}}{m_{\text {chip }} C_{p}}
\end{gathered}
$$

The temperature at the tool-chip interface $T_{i n t}$ can be calculated using (27) [10].

$$
T_{i n t}=T_{w}+\frac{(1-\xi) F_{s h} V_{s h}}{m_{\text {chip }} C_{p}}+\Psi \Delta T_{M}
$$

Where $\Psi$ is the ratio of tool-chip interface temperature rise to the maximum temperature rise of the chip [11]. In this paper, this value was assumed to be 0.9 . Using these temperatures, the Johnson-Cook constitutive equation is used again to determine the shear flow stress along the tool-chip interface.

$$
\tau_{\text {chip }}=\frac{1}{\sqrt{3}}\left(A+B \varepsilon_{i n t}^{n}\right)\left(1+C \ln \left(\frac{\dot{\varepsilon}_{i n t}}{\dot{\varepsilon}_{0}}\right)\right)\left(1-\left(\frac{T_{i n t}-T_{w}}{T_{M}-T_{w}}\right)^{m}\right)
$$

At this point, the values of $\tau_{\text {int }}$ and $\tau_{\text {chip }}$ are compared. After running these calculations for every value of $\phi$, the final value of $\phi$ is chosen such that the difference between $\tau_{\text {int }}$ and $\tau_{\text {chip }}$ is minimized. For the next check, the normal stress at the tool-chip interface is calculated. This is done with two method: one using the resultant force $\sigma_{N}$, and the other using stress boundary conditions at point B $\left(\sigma_{N}^{\prime}\right)$. These are given in (29) and (30) [10].

$$
\begin{gathered}
\sigma_{N}=\frac{N}{L_{i n t} w} \\
\sigma_{N}^{\prime}=\sigma_{A B}\left(1+\frac{\pi}{2}-2 \gamma-2 C_{0} n_{e q}\right)
\end{gathered}
$$

Similar to the determination of the value for $\phi$, the values of $\sigma_{N}$ and $\sigma_{N}^{\prime}$ are compared, and the value of $C_{0}$ is chosen such that the difference between them in minimized.

The final determination that is needed is the value of $\zeta$. As previously mentioned, all possible values of $F_{c u t}$ are compared. The value of $\zeta$ is chosen corresponding to the minimum value of $F_{c u t}$. At this point, the three variables discussed at the beginning of this analysis are determined $\left(\phi, C_{0}\right.$, and $\left.\zeta\right)$, and the forces are known.

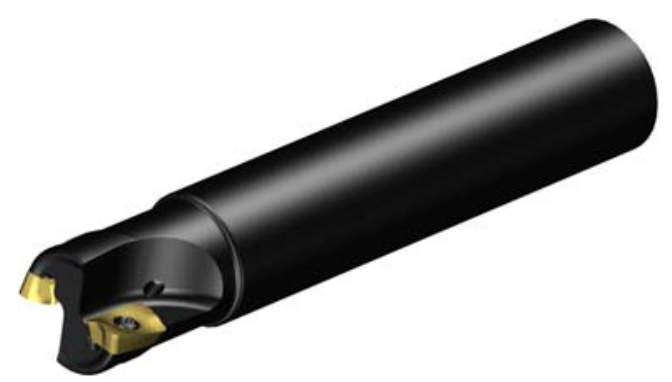

Figure 2. Image of milling tool R390-020A20-11L [12] 
However, this is only the solution for this position of the tool. To continue, the cutting force prediction is stored, the angle of the milling tool $\theta$ is incremented up, and the entire process repeats.

\section{EXPERIMENTAL VALIDATION}

In this work, the workpiece material is chosen to be AISI 4340 steel, hardened to $47 \pm 1$ HRC. The Johnson-Cook parameters for hardened alloy steel 4340 are available in the literature [1]. In the event that these parameters are not available for a given material, then the necessary experiments will need to be performed to determine the values. With these parameters known, the model presented in this paper can be applied to any workpiece-tool combination.

The machining operation being performed is face milling of a rectangular block. This operation allows for tests to be conducted at half-immersion, without wasting a large amount of material for one pass. The model should maintain its validity when applied to shoulder milling cases, or operations with a different immersion, but only the half-immersion, face milling case was verified experimentally in this work.

\section{A. Milling Tool Selection}

The tool is a Sandvik-Coromant milling tool, R390-020A2011L. An image of this tool can be seen in Fig. 2. This tool has two cutting edges, with one of the edges designed to perform a roughing cut, and the other is designed to perform a finishing cut. This is accomplished by having the finishing edge experience a smaller chip load than the roughing edge.

\section{B. Input Parameters}

In order to analyze the cutting forces for a milling process, several input parameters must be known. First, the cutting conditions that describe the operation should be known. For this analysis, the cutting parameters and material properties are listed in Table 2 and Table 3 respectively.

\section{TABLE II. CUTTING PARAMETERS}

\begin{tabular}{|l|c|}
\hline Parameter & Value \\
\hline Tool Diameter $(D)$ & $20 \mathrm{~mm}$ \\
\hline Number of Cutting Edges $(N)$ & 2 \\
\hline Tool Rake Angle $(\gamma)$ & $14.5^{\circ}$ \\
\hline Axial Depth of Cut $(a)$ & $1 \mathrm{~mm}$ \\
\hline Entry Angle, Down Milling $\left(\theta_{\text {start }}\right)$ & $90^{\circ}$ \\
\hline Exit Angle, Down Milling $\left(\theta_{\text {exit }}\right)$ & $180^{\circ}$ \\
\hline
\end{tabular}

TABLE III.

MATERIAL PROPERTIES [1]

\begin{tabular}{|l|c|}
\hline Property & Value \\
\hline Yield Stress $(A)$ & $950 \mathrm{MPa}$ \\
\hline Hardening Stress $(B)$ & $725 \mathrm{MPa}$ \\
\hline Strain Hardening Coefficient $(C)$ & 0.015 \\
\hline Strain-Rate Hardening Exponent $(n)$ & 0.375 \\
\hline Thermal Softening Coefficient $(m)$ & 0.625 \\
\hline Reference Strain Rate $\left(\dot{\varepsilon}_{0}\right)$ & 3500 \\
\hline Specific Heat $\left(C_{p}\right)$ & $477 \mathrm{~J} / \mathrm{kgK}$ \\
\hline Thermal Conductivity $(K)$ & $44.5 \mathrm{~W} / \mathrm{mK}$ \\
\hline
\end{tabular}

A series of six tests were carried out to determine the validity of the mathematical model. The tests were performed on a HAAS VF-2 CNC milling machine. The forces were captured using a Kistler dynamometer, National Instruments data acquisition card $9250 \mathrm{~B}$. In these tests, different combinations of cutting speed and feed rate were used. Cutting conditions for the experiments can be found in Table 4 . Figs. 3 to 8 show the comparison between the calculated cutting forces and the measured forces from the corresponding experiments, with respect to the angle of rotation of the milling tool.

For each of the cutting tests, the measured cutting force data and the calculated cutting force from the model are compared. A total of two tool rotations are plotted for each test. It can be seen that each of the tests shows good agreement between the trends of the forces with respect to the tool position. The shapes of these graphs match what was expected, as the half-immersion down milling case has the cutting edge suddenly engage the workpiece material, resulting in a sudden large chip load. As the tool rotates, the chip load decreases, causing the cutting forces to decrease as well. The force reaches zero when the cutting edge disengages with the workpiece, and the chip is removed. When comparing the percent error between the calculated and measured forces, the largest error was found to be approximately $19 \%$. This shows good agreement between the model and the measured forces.

TABLE IV.

EXPERIMENTAL CONDITIONS

\begin{tabular}{|l|l|l|}
\hline Test No. & Cutting Speed $(\mathbf{m} / \mathbf{m i n})$ & Feed Rate $(\mathbf{m m} / \mathbf{m i n})$ \\
\hline 1 & 125 & 800 \\
\hline 2 & 100 & 800 \\
\hline 3 & 75 & 800 \\
\hline 4 & 125 & 1000 \\
\hline 5 & 100 & 1000 \\
\hline 6 & 75 & 1000 \\
\hline
\end{tabular}

Test 1

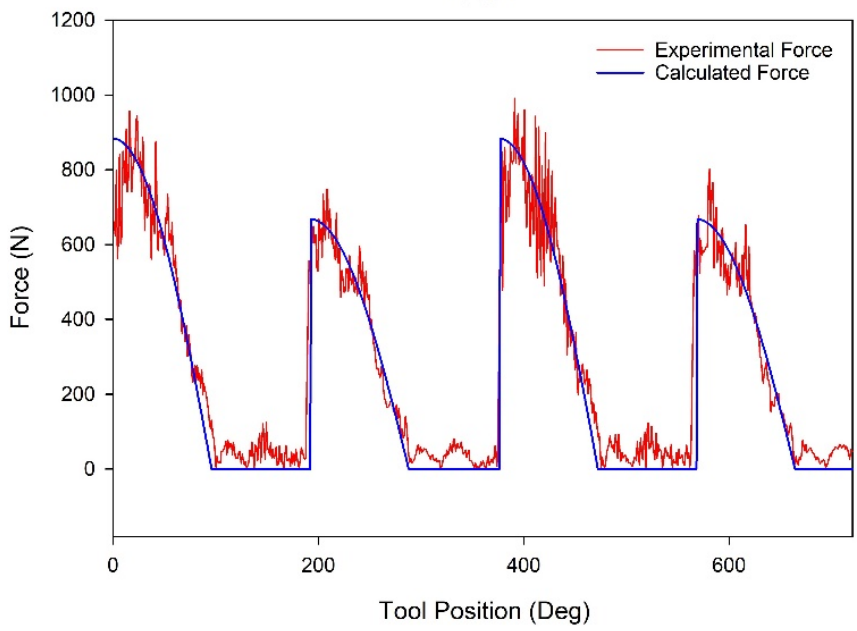

Figure 3. Calculated vs. experimental resultant force $\left(V_{c}=125 \mathrm{~m} / \mathrm{min}, f=800\right.$ $\mathrm{mm} / \mathrm{min}$ ) 
Test 2

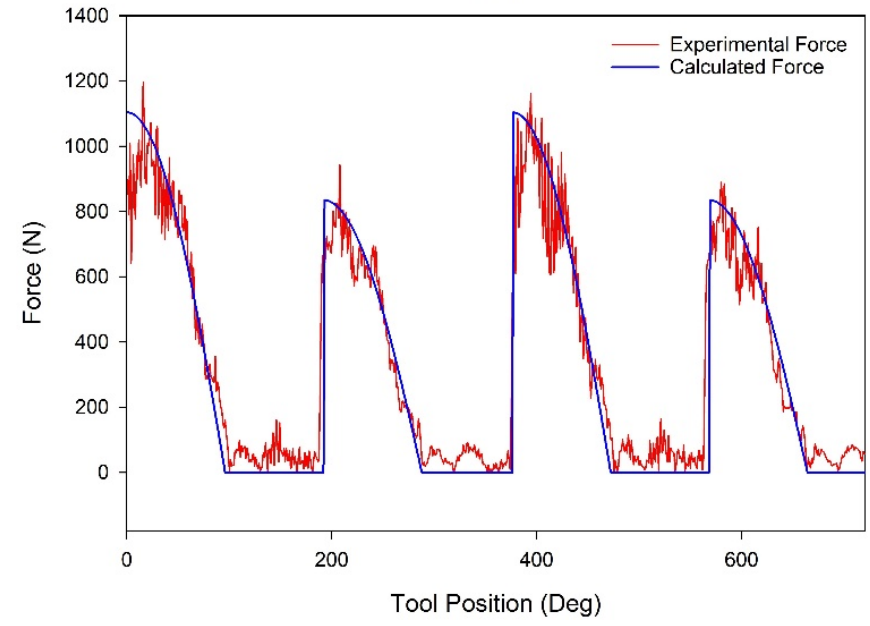

Figure 4. Calculated vs. experimental resultant force $\left(V_{c}=100 \mathrm{~m} / \mathrm{min}, f=800\right.$ $\mathrm{mm} / \mathrm{min}$ )

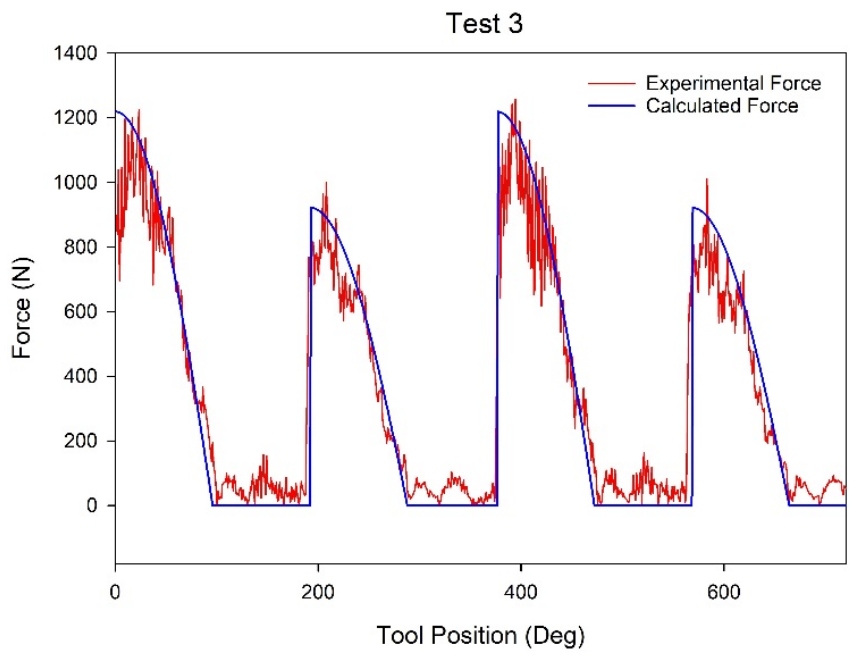

Figure 5. Calculated vs. experimental resultant force $\left(V_{c}=75 \mathrm{~m} / \mathrm{min}, f=800\right.$ $\mathrm{mm} / \mathrm{min}$ )

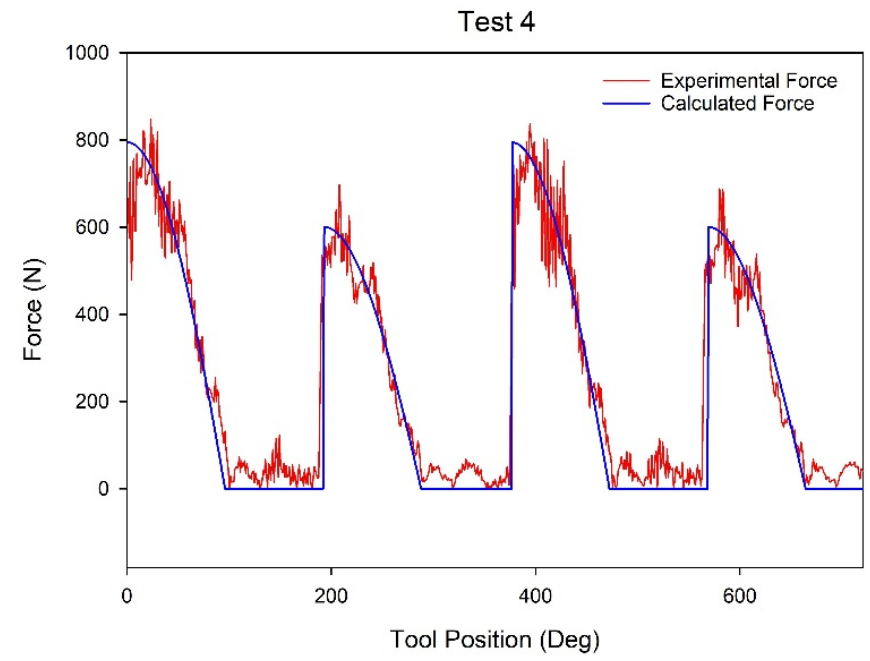

Figure 6. Calculated and experimental resultant force $\left(V_{c}=125 \mathrm{~m} / \mathrm{min}, f=\right.$ $1000 \mathrm{~mm} / \mathrm{min}$ )

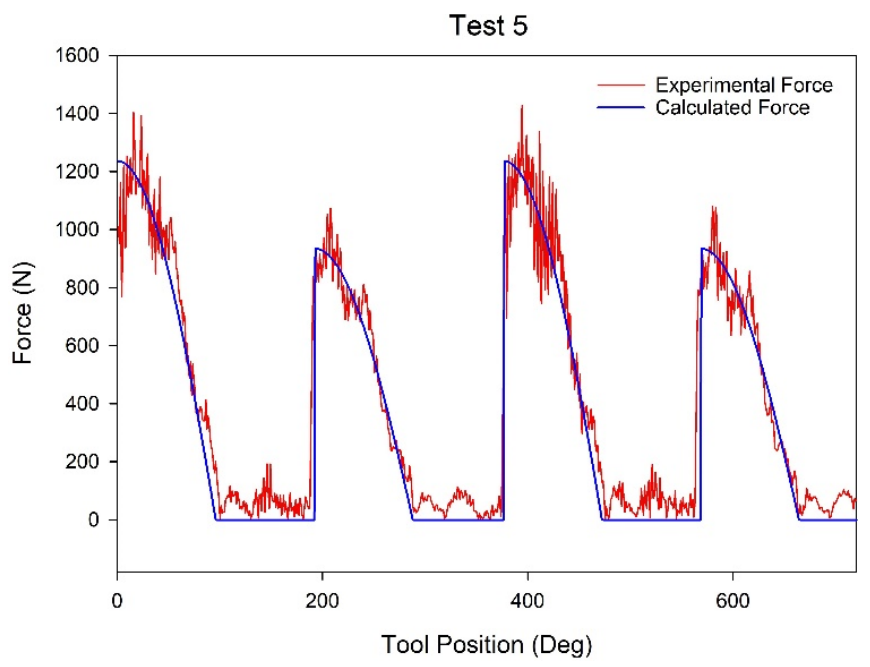

Figure 7. Calculated vs. experimental resultant force $\left(V_{c}=100 \mathrm{~m} / \mathrm{min}, f=\right.$ $1000 \mathrm{~mm} / \mathrm{min}$ )

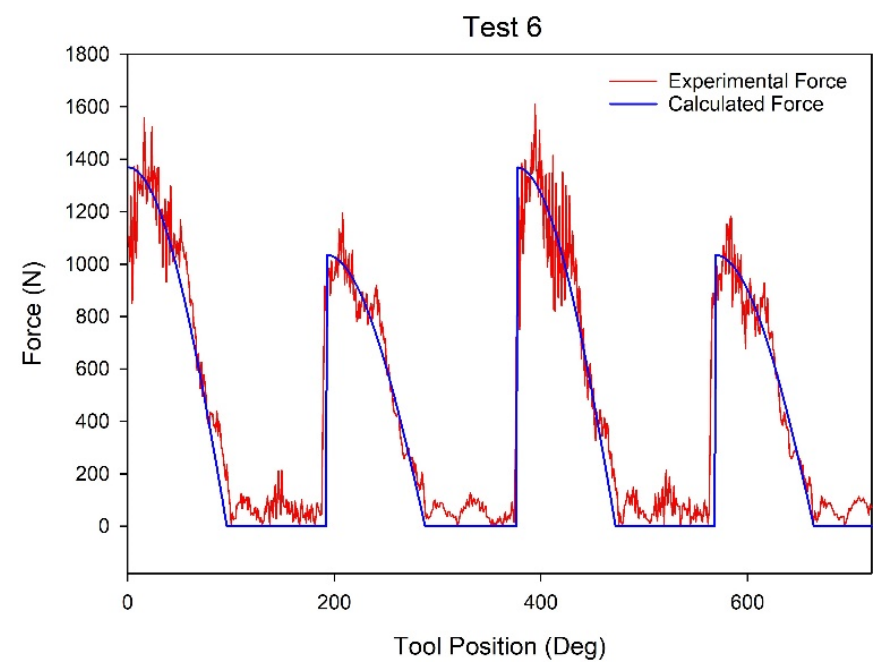

Figure 8. Calculated vs. experimental resultant force $\left(V_{c}=75 \mathrm{~m} / \mathrm{min}, f=1000\right.$ $\mathrm{mm} / \mathrm{min}$ )

\section{CONCLUSION}

This paper presents an Oxley based force model to predict the cutting forces during face milling of hardened steel 4340 using indexable milling tool with two edges, one for roughing and one for finishing. The model is run in a series of iterative loops to determine the cutting forces at any given tool position. Therefore, the values can be plotted as a function of the tool's rotation. Experiments considering six different combinations of cutting speed and feed rate are used to validate the mathematical model.

\section{REFERENCES}

E.-G. Ng, T. I. El-Wardany, M. Dumitrescu, and M. A. Elbestawi, "Physics-based simulation of high speed machining," Machining science and technology, vol. 6, no. 3, pp. 301-329, 2002.

P. L. B. Oxley and M. C. Shaw, "Mechanics of machining: an analytical approach to assessing machinability," 1990. 
[3] M. E. Merchant, "Mechanics of the metal cutting process. I. Orthogonal cutting and a type 2 chip," Journal of applied physics, vol. 16, no. 5, pp. 267-275, 1945.

[4] R. Hu, P. Mathew, P. Oxley, and H. Young, "Allowing for end cutting edge effects in predicting forces in bar turning with oblique machining conditions," Proceedings of the Institution of Mechanical Engineers, Part C: Journal of Mechanical Engineering Science, vol. 200, no. 2, pp. 89-99, 1986.

[5] J. Arsecularatne, P. Mathew, and P. Oxley, "Prediction of chip flow direction and cutting forces in oblique machining with nose radius tools," Proceedings of the Institution of Mechanical Engineers, Part B: Journal of Engineering Manufacture, vol. 209, no. 4, pp. 305-315, 1995.

[6] W. Hastings, P. Mathew, P. Oxley, and H. Ford, "A machining theory for predicting chip geometry, cutting forces etc. from work material properties and cutting conditions," Proceedings of the Royal Society of London. A. Mathematical and Physical Sciences, vol. 371, no. 1747, pp. 569-587, 1980.

[7] H.-T. Young, P. Mathew, and P. Oxley, "Predicting cutting forces in face milling," International Journal of Machine Tools and Manufacture, vol. 34, no. 6, pp. 771-783, 1994.

[8] D. Lalwani, N. Mehta, and P. Jain, "Extension of Oxley's predictive machining theory for Johnson and Cook flow stress model," Journal of materials processing technology, vol. 209, no. 12-13, pp. 53055312,2009

[9] H. Bao and M. Stevenson, "A basic mechanism for built-up edge formation in machining," CIRP Ann, vol. 25, no. 1, pp. 53-57, 1976.

[10] C. K. Sagar, T. Kumar, A. Priyadarshini, and A. K. Gupta, "Prediction and optimization of machining forces using oxley's predictive theory and RSM approach during machining of WHAs," Defence Technology, 2019.

[11] L. Pang, A. Hosseini, H. Hussein, I. Deiab, and H. Kishawy, "Application of a new thick zone model to the cutting mechanics during end-milling," International Journal of Mechanical Sciences, vol. 96, pp. 91-100, 2015.

[12] sandvik.coromant.com. [Online]. Available: https://productinformation.sandvik.coromant.com/s3/documents/pic tures/pict-3d-view-on-item-

level/preview/202161469_d50_0_0 t104_04.jpg 